Proceedings

\title{
Derivation of Appropriate Conditions for Additive Manufac- turing Technology using Hot-Wire Laser Method ${ }^{+}$
}

\author{
Song Zhu11,*, You Nakahara ${ }^{1}$, Hideki Aono ${ }^{2}$, Ryo Ejima ${ }^{3}$ and Motomichi Yamamoto ${ }^{1}$ \\ 1 Graduate School of Engineering, Hiroshima University, Japan; \\ zhusong816@gmail.com (S.Z.): m206583@hiroshima-u.ac.jp (Y.N.): motoyama@hiroshima-u.ac.jp (M.Y.) \\ 2 Matsumoto Kikai Co., LTD; h_aono@mac-wels.co.jp \\ 3 Marubun Corp.; ryo_ejima@marubun.co.jp \\ * zhusong816@gmail.com; +81-70-1260-2026 (S.Z.): motoyama@hiroshima-u.ac.jp, +81-82-424-7815 (M.Y.) \\ + Hiroshima, Japan; 2021/2/6
}

Citation: Zhu, S.; Nakahara, Y.; Aono, H.; Ejima, R.; Yamamoto, M. Derivation of Appropriate Conditions for Additive Manufacturing Technology using Hot-Wire Laser Method. 2021, 3, x

https://doi.org/10.3390/xxxxx

Published: 22 February 2021

Publisher's Note: MDPI stays neutral with regard to jurisdictional claims in published maps and institutional affiliations.

Copyright: (c) 2021 by the authors. Submitted for possible open access publication under the terms and conditions of the Creative Commons Attribution (CC BY) license (http://creativecommons.org/licenses/by/4.0/).

\begin{abstract}
The aim of this research was to develop a high-efficiency and high-material-utilization additive manufacturing technology using the hot-wire laser method. In this study, the optimization of process conditions using a combination of a high-power diode laser with a relatively large-rectangular laser spot and a hot-wire system was investigated. The effects of process parameters such as laser power, process speed, and wire feeding rate (wire feeding speed / process speed) on a bead appearance and cross-sectional characteristics (e.g. effective width, effective height, maximum height, and near net shape rate) were studied in detail. The process phenomena during the multilayer deposition were investigated by in-situ observation via a high-speed camera.
\end{abstract}

Keywords: AM technology; Diode laser; Hot wire; High material utilization; High efficiency

\section{Introduction}

In recent years, researches, developments, and practical applications of Additive Manufacturing (AM) technologies such as three-dimensional(3D) printing processes have been actively carried out [1-6]. As opposed to traditional subtractive manufacturing methodologies, AM technology is to continuously accumulate materials by adding layer-bylayer and complete the 3D parts through computer-controlled technology [7-10].

In a recent study, the AM technology can be categorized into three types in terms of heat sources: wire and arc additive manufacturing (WAAM), electron beam additive manufacturing(EBAM), and laser additive manufacturing (LAM). Although the WAAM technology has convenient and economical efficient advantages compared with other AM technology, it has the problems of high dilution, distortion, and small tolerances of process conditions [11-12]. The EBAM technology also has some problems such as the high cost of equipment and the vacuum precision welding environment [13-14]. The LAM technology using powder materials has an advantage of high-precision while a lot of problems, such as a low deposition rate and higher material cost [15-16]. Moreover, about a small amount of $(20 \%)$ of the metal powder could be effectively used, while the metal wire can greatly improve the utilization rate of the material [17]. Hence, the deposited material is prefabricated as metal wire instead of metal powder. However, due to the low laser absorption of cold wire, the process using cold wire materials also has a lot of problems, such as spatter and fume generations, difficulties of heat input control and wire melting, small tolerances of process conditions, and so on [18-19].

The laser hot-wire (LHW) is a novel welding process which has dual heat sources. A convertible laser beam serves as the main heat source, and the additional heat source is Joule heat generated via the current, which heated the filler cold-wire to its melting point during the deposition. The advantage of the laser hot-wire method can effectively increase productivity, and the degree of freedom of control of the material is high. Compare with the cold-wire laser method, this method has high material utilization and forms a model 
with a wider range of bead width at a high deposition rate [20-21]. Therefore, the development of laser hot-wire AM technology is very meaningful and valuable.

In this research, the high-efficiency AM technology using a combination of a highpower diode laser with a relatively large laser spot a hot-wire system is studied. The effect of process parameters (Laser power, process speed, and wire feeding rate) on the melting phenomenon was systematically studied. Moreover, The effects of process parameters (laser power, process speed, wire feeding rate) on the bead appearance and cross-section characteristics were also investigated. In this paper, we report the results of the derivation of appropriate process conditions to achieve higher efficiency, sound shape, and 15-layer large-scale wall modeling.

\section{Materials and experimental methods}

The Z3321-YS308L with a 1.2-mm diameter was used as a filler material. A $590 \mathrm{MPa}$ class steel plate having 9-mm thickness was used as a base metal. Table 1 shows the process conditions and Fig. 1 shows the experimental set-up. The wide and narrow (1.6 x 11 $\mathrm{mm}$ ) rectangular laser spot was applied. The laser power, process speed, and wire feeding rate (wire feeding rate: wire feeding speed / process speed) were varied as a parameter respectively. Ar gas was used for shielding with a shielding box. The bead appearance evaluation, the cross-sectional observation, and measurement of bead sizes were performed. The effective width, effective height, maximum height, and near net shape rate were measured on three cross-sections for each bead as shown in Fig. 2.

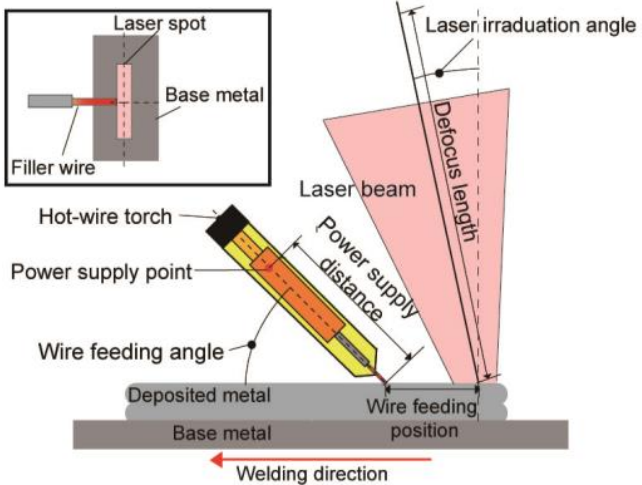

Figure 1. Experimental set-up.

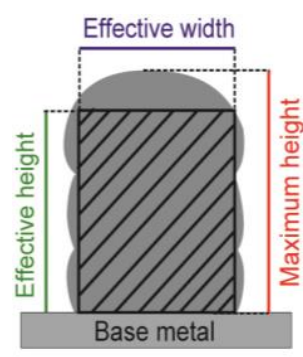

Near net shape rate $=$

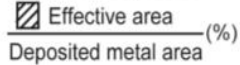

Figure 2. Cross-sectional evaluation.

Table 1. Process conditions.

\begin{tabular}{cc}
\hline Content & Value \\
\hline Number of layers & 3 \\
Laser power, $\mathrm{kW}$ & $3.3 \sim 5.5$ \\
Laser irradiation angle, deg & 5 \\
Laser spot size, $\mathrm{mm}$ & $1.6 \times 11$ \\
Process speed, $\mathrm{m} / \mathrm{min}$ & $0.24 \sim 0.5$ \\
Wire feeding speed, $\mathrm{m} / \mathrm{min}$ & $6 \sim 20$ \\
Wire feeding rate & $20 \sim 40$ \\
Wire feeding angle, deg & 45 \\
Shielding gas (Ar), L/min & 30 \\
\hline
\end{tabular}

\section{Results}

Figure 3 shows the evaluated result of bead appearance on the three-layer deposition for each combination of process conditions; (a) process speed and laser power, (b) wire 
feeding rate laser power. It can be seen from Fig. 3(a) that when the wire feed rate is fixed, each process speed has a limitation of the lowest laser power. In other words, when the energy heat input (see in equations (1)) is below a certain limit, defects will appear on the bead surface. Moreover, it can be concluded from Fig. 3(b) that when the process speed is fixed, the laser hot-wire method can achieve a wide range of process conditions deposition, but each wire feeding rate has a limitation of the lowest energy heat input. It is concluded that the bead with some typical defects like wire stubbing (denoted by $\times$ ) was obtained at relatively low laser power under different process speed and wire feeding rate. In contrast, sound bead with no defects (denoted by o) was obtained at relatively high laser power under proper process speed of $0.3-0.5 \mathrm{~m} / \mathrm{min}$ and wire feeding rate of 20 40.

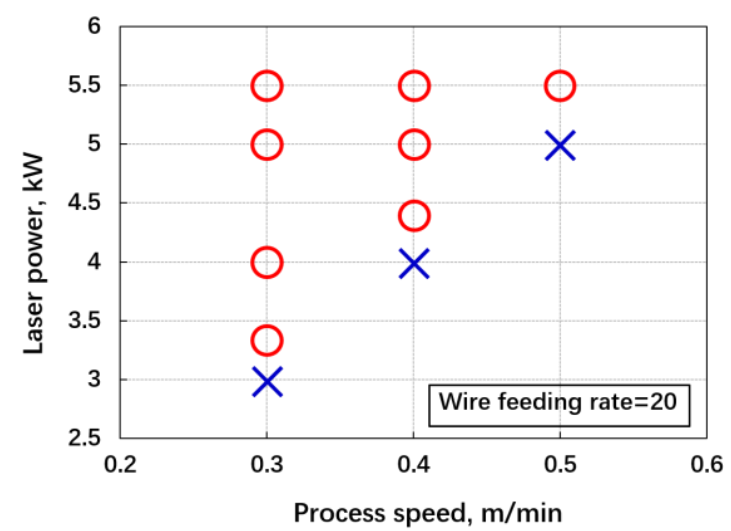

(a)

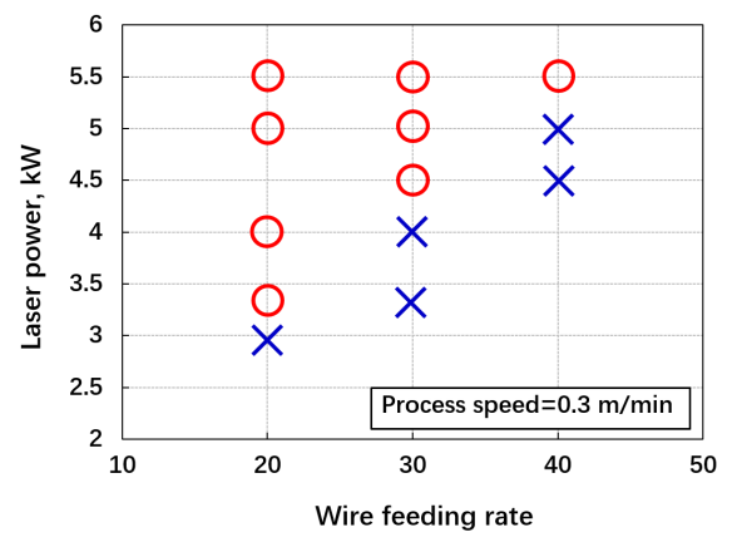

(b)

Figure 3. The bead evaluation of three-layer for each combination of process parameters: (a) Process speed and laser power; (b) Wire feeding rate and laser power.

Figure 4 shows the evaluated results of bead shape when the process speed was varied at a constant wire feeding rate of 20,30 , and a constant laser power of $5.5 \mathrm{~kW}$. It is observed that the effective width decreases, the effective height, and maximum height increase, the near net shape rate increases with the increase of the process speed. All measured values of the wire feeding speed of 30 improve compared with the values of the wire feeding speed of 20. In other words, the feeding rate of 20 could not supply enough volume of deposit metal for the wide laser spot of $11 \mathrm{~mm}$ on the proposed high-efficiency AM process.

Figure 5 shows the evaluated results of bead shape and Fig. 6 shows the cross-sections when the wire feeding rate was varied around 30 under the constant laser power of $5.5 \mathrm{~kW}$ and a constant process speed of $0.36 \mathrm{~m} / \mathrm{min}$. It is found that the effective bead width over $10 \mathrm{~mm}$ for the laser spot width of $11 \mathrm{~mm}$, effective height almost $9 \mathrm{~mm}$, maximum height almost $11 \mathrm{~mm}$, and near net shape rate of $80 \%$ could be obtained under the wire feeding rate of 33.3 .

Figure 7 shows the bead appearance and cross-sectional observation of 15-layer sample using the optimum conditions obtained from the above investigations. It is observed that the smooth and sound bead could be obtained even if all process conditions are fixed from the $1^{\text {st }}$ layer to final the $15^{\text {th }}$ layer. Moreover, the effective height over $50 \mathrm{~mm}$, maximum height over $55 \mathrm{~mm}$, effective width over $8 \mathrm{~mm}$, and near net shape rate of $83 \%$ could be obtained with very high efficiency using only 15 layers. 


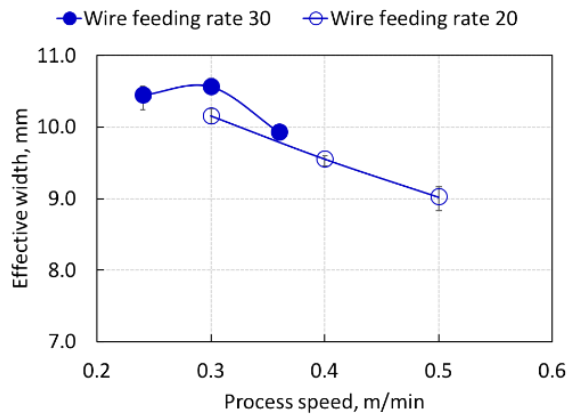

(a)
$-\mathrm{EH}$ Wire feeding rate $30 \rightarrow \mathrm{MH}$ Wire feeding rate 30 $\square \mathrm{EH}$ Wire feeding rate $20 \diamond \mathrm{MH}$ Wire feeding rate 20

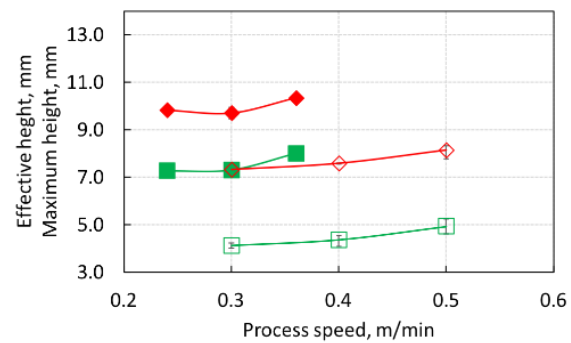

(b)

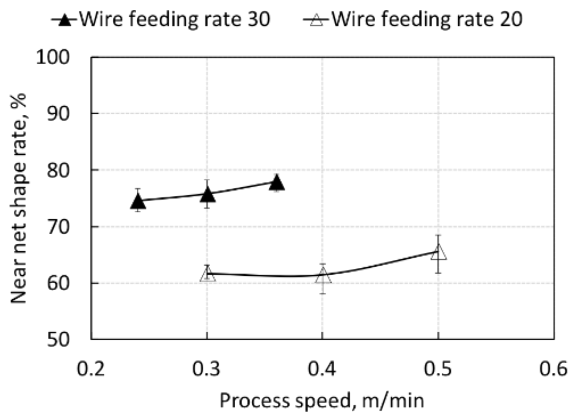

(c)

Figure 4. Bead shape evaluation ( $P=5.5 \mathrm{~kW}$ ): (a) Effective width; (b) Effective height and Maximum height; (c) Near net shape rate.

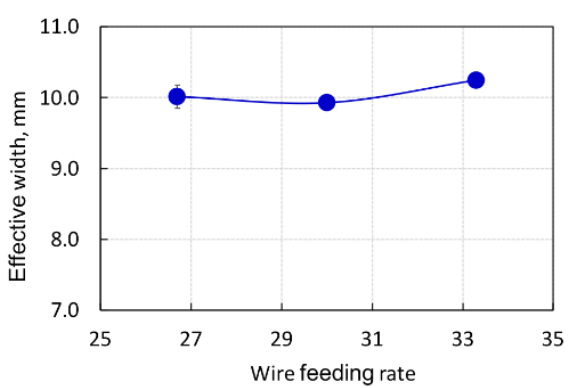

(a)

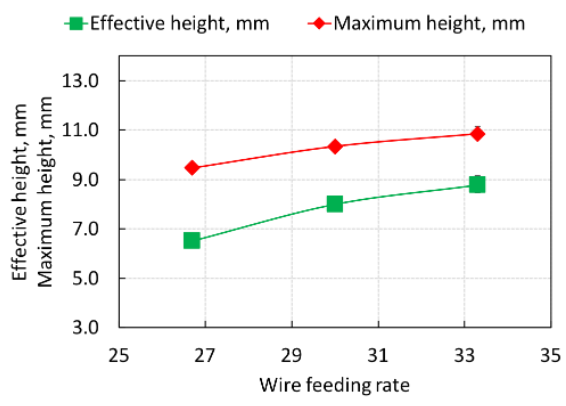

(b)

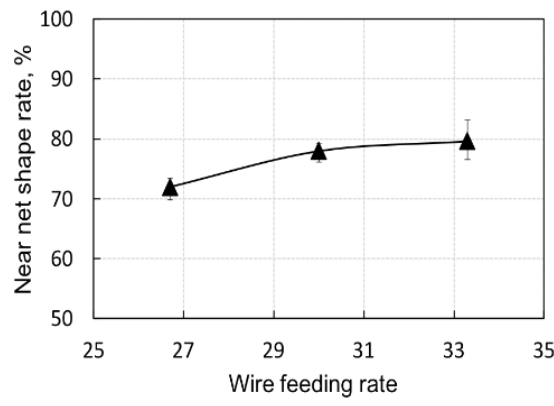

(c)

Figure 5. Bead shape evaluation ( $P=5.5 \mathrm{~kW}, V_{p}=0.36 \mathrm{~m} / \mathrm{min}$ ): (a) Effective width; (b) Effective height and Maximum height; (c) Near net shape rate.
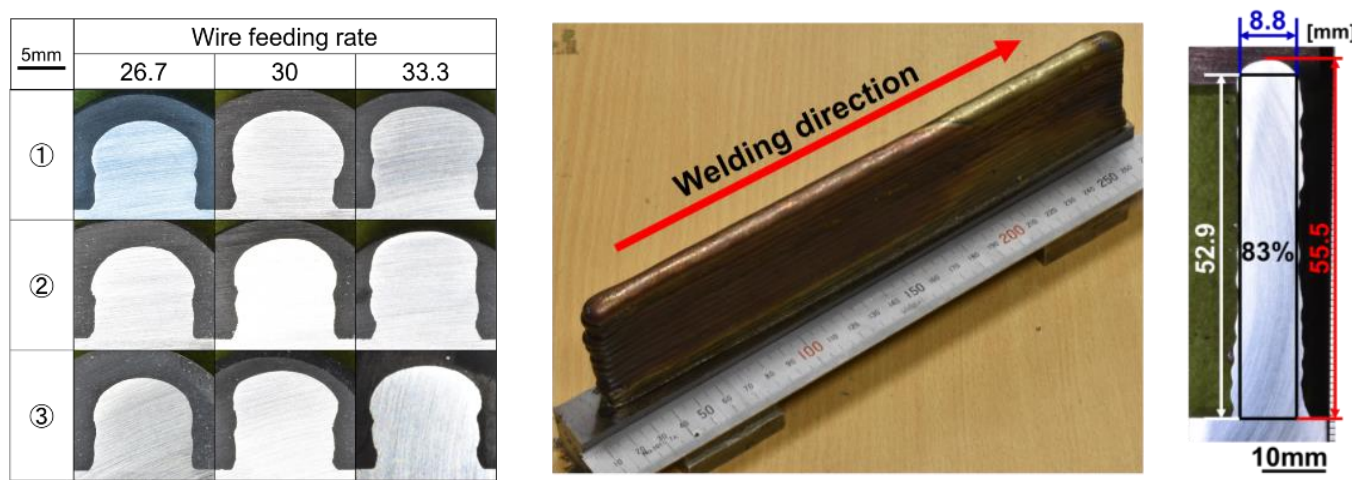

Figure 6. Cross-sections.

Figure 7. Bead appearance and cross-sectional observation (15-layer).

\section{Discussion}

\subsection{Three-layer deposition}

Figure 8(a) - 8(d) show the bead appearance and high-speed camera images of the three-layer deposition under different process speed and laser power combinations. When a process speed $\left(V_{p}\right)$ of $0.3 \mathrm{~m} / \mathrm{min}$, laser power $(P)$ of $4 \mathrm{~kW}$, and wire feeding rate (WFR) of 20, the sound bead with no defects was obtained. As shown in Fig. 8(a), the filler wire melted continuously at a low process speed. When a higher process speed $(0.4,0.5$ $\mathrm{m} / \mathrm{min}$ ) was applied when the wire feeding rate kept constant, the bead with typical defects was obtained (see in Figs. 8(b) and 8(d)). The energy heat input decreases with the increase in process speed, the insufficient energy heat input which resulted in the filler 
wire cannot melt completely and attributes to the misalignment between the filler wire and molten pool, then forming the spikes during the deposition. In other words, at a relatively low energy heat input, it will result in a shallower weld penetration in the previous layer, the filler wire cannot be feeding smoothly and continuously. When a process speed of $0.4 \mathrm{~m} / \mathrm{min}$, laser power increased to $5 \mathrm{~kW}$, as shown in Fig. 8(c), the filler wire feeding continuously into the molten pool area and the sound bead was formed. It is concluded that increasing the laser power can have enough energy heat input to generate deep weld penetration for the previous layer to ensure that the filler wire can be fully melted.

Figure 9(a) - 9(d) show the bead appearance and high-speed camera images of the three-layer deposition under different wire feeding rate and laser power combinations. As shown in fig.9(a), when a suitable wire feeding rate for a fixed combination of laser power and process speed, what produced a stable welding process and a sound bead (see in Figs. 9(a) and 9(c)). When the wire feeding rate $(30,40)$ was excessively high for a fixed combination of laser power and process speed (see in Figs. 9(b) and 9(d)), the filler wire interacted momently with the laser irradiation, results in the unmelt and nearly solid filler wire collide with the bottom of the substrate. A misalignment between the filler wire and molten pool caused the filler wire to slip out of the molten pool. In this process, the irregular bead with typical defects was obtained.

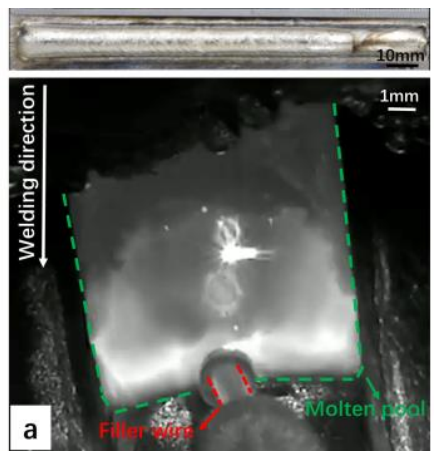

(a)

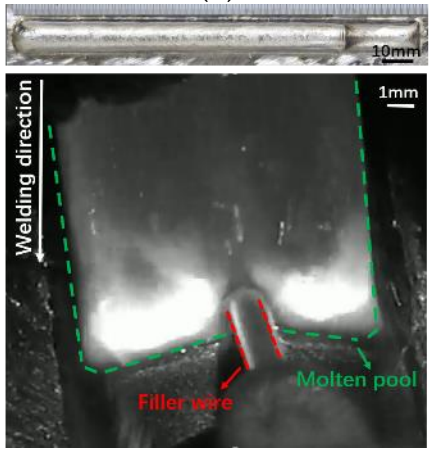

(c)

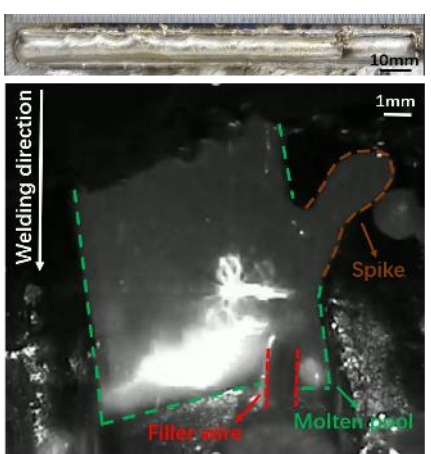

(b)

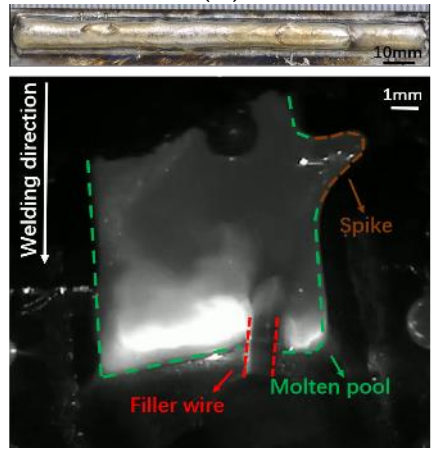

(d)

Figure 8. Melting phenomenon for varied as process speed and laser power: (a) $P=4 \mathrm{~kW}, V_{p}=0.3 \mathrm{~m} / \mathrm{min}$; (b) $P=4 \mathrm{~kW}, V_{p}$ $=0.4 \mathrm{~m} / \mathrm{min} ;$ (c) $P=5 \mathrm{~kW}, V_{p}=0.4 \mathrm{~m} / \mathrm{min} ;$ (d) $P=5 \mathrm{~kW}, V_{p}=0.5 \mathrm{~m} / \mathrm{min}$. 


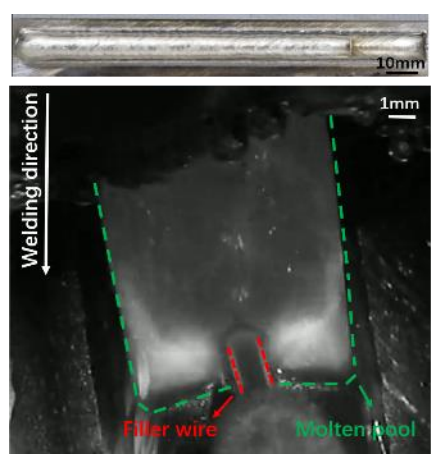

(a)

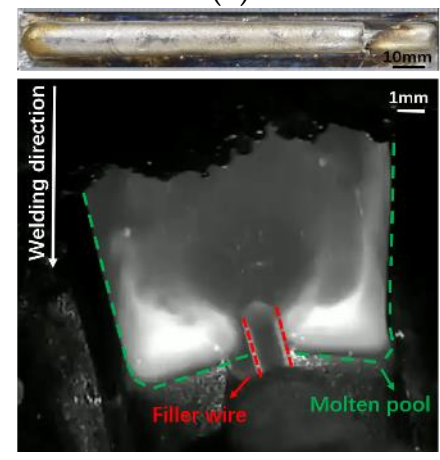

(c)

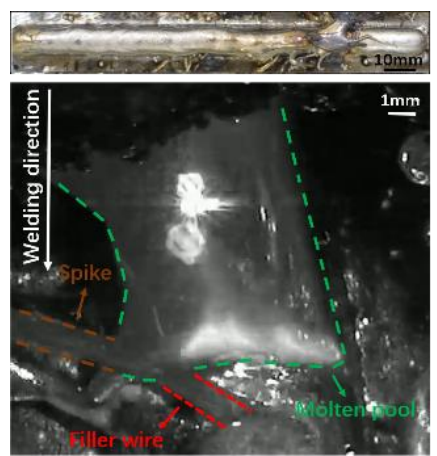

(b)

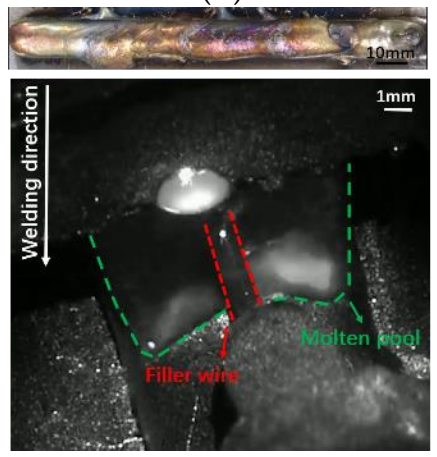

(d)

Figure 9. Melting phenomenon for varied as wire feeding rate and laser power: (a) $P=3.3 \mathrm{~kW}, \mathrm{WFR}=20$; (b) $P=3.3 \mathrm{~kW}$, $\mathrm{WFR}=30$; (c) $P=4.5 \mathrm{~kW}, \mathrm{WFR}=30 ;$ (d) $P=4.5 \mathrm{~kW}$, WFR $=40$.

In order to combine the process parameters of laser power, process speed, laser spot size, and wire feeding speed, the evaluation of the energy heat input $(\mathrm{J} / \mathrm{mm} 3)$ and wire feeding rate were shown in equations (1), (2). $P$ is the laser power, in $W ; A s$ is the area of laser spot size, in $\mathrm{mm} ; V_{p}$ is the process speed, in $\mathrm{m} / \mathrm{min} ; V_{f}$ is wire feeding speed, in $\mathrm{m} / \mathrm{min}$.

$$
\begin{gathered}
\text { Energy heat input }=\frac{P}{\mathrm{~A}_{s} * \mathrm{~V}_{p}} \\
\text { Wire feeding rate }=\frac{\mathrm{V}_{f}}{\mathrm{~V}_{p}}
\end{gathered}
$$

Figure 10 shows the bead evaluation map produced at each process condition depended on the energy heat input (Y-axis) and wire feeding rate (X-axis). It can be observed that bead with typical defects area region increases with the increase of wire feeding rate, and decreases with the increase of energy heat input. This confirms the fact that the defects can be eliminated by either increasing the energy heat input or decreasing the wire feeding rate. 


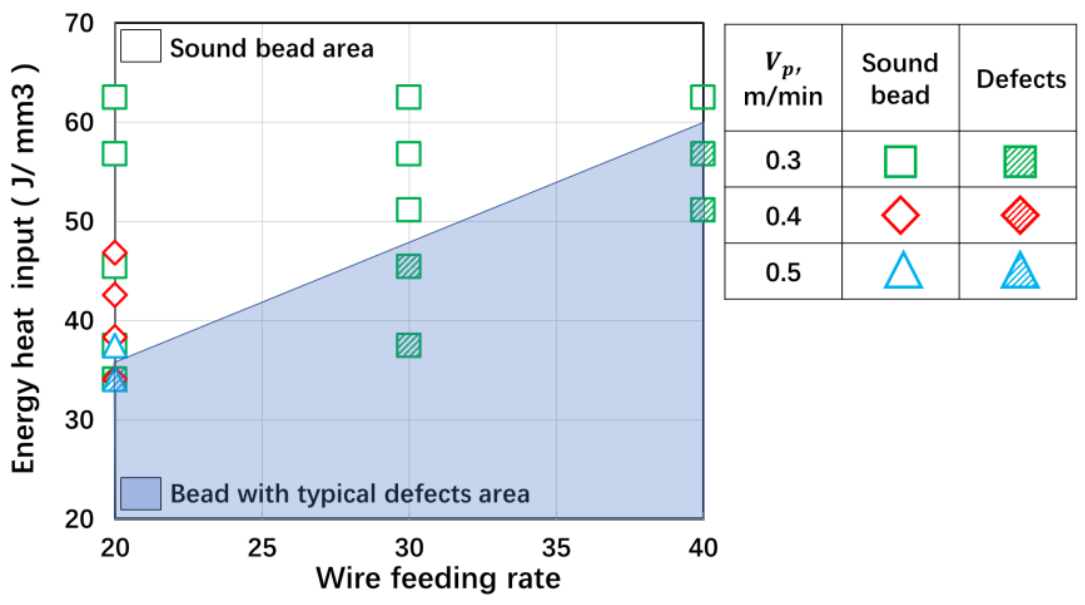

Figure 10. The map illustrating the three-layer deposition.

\subsection{Effects of process parameters on cross-sectional characteristics}

The cross-sectional characteristics (e.g. effective width, effective height, maximum height, and near net shape rate) mainly influenced by the process speed when the other process parameters were fixed (see in fig.4). The effective width decreases, the effective height, maximum height, and the near net shape rate increase with the increases of the process speed. This result is attributed to the increased process speed produced lower the energy heat input, hence a smaller size of the substrate was melted and a smaller bead was formed under high process speed. In other words, increasing the processing speed means that the energy heat input is reduced, so that the width of the substrate and the previous layer will be narrowed. Meanwhile, the amount of wire fed per unit time is constant, the width of the deposited layer will inevitably decreases results in the height of each layer increases.

Wire feeding rate is another important process parameter. When the laser power and welding speed are fixed, it means that the energy heat input is constant, so the change in the width of the bead is not obvious. In additions, the increase in wire feeding rate increased the effective height and maximum height (see in fig.5). This may due to the wire feeding rate increased, more filler materials were deposited onto the molten pool producing and the height Increase significantly. Hence, a thicker three-layer deposition can be obtained under a higher wire feeding rate.

\section{Conclusion}

Stable deposition phenomena and the sound bead could be obtained even when the process conditions are greatly changed, and the degree of freedom in selecting the process conditions is very high by using a combination of a high-power diode laser with a relatively large laser spot a hot-wire system. The smooth and sound bead could be obtained even if all process conditions are fixed from the $1^{\text {st }}$ layer to the $15^{\text {th }}$ layer. Large-scale wall modeling of more than $50 \mathrm{~mm}$ in height, $8 \mathrm{~mm}$ in width, and $250 \mathrm{~mm}$ in length could be fabricated efficiently and stably by using the laser hot-wire AM technology. 


\section{References}

1. DebRoy, T.; Wei, H.L.; Zuback, J.S.; Mukherjee, T.; Elmer, J.W.; Milewski, J.O.; Beese, A.M.; Wilson-Heid, A.; De, A.; Zhang, W. Additive manufacturing of metallic components - Process, structure and properties. Prog. Mater. SCI. 2018, 92, $112-224$.

2. Milewski, J.O. Additive manufacturing of metals. Springer Ser. Mater. Sci. 2017, 258, 7-33.

3. Cawley, J.D. Solid freeform fabrication of ceramics. Curr. Opin. in Solid State Mater. Sci. 1999, 4, 483-489.

4. Sandeep; Deepak, C. Comparison and analysis of different 3D printing techniques. Int. J. Eng. Technol. 2017, 8, $264-272$.

5. Syed, A.M.T.; Elias, P.K.; Amit, B.; Susmita, B.; Lisa, O.; Costas, C. Additive manufacturing: scientific and technological challenges, market uptake and opportunities. Mater. Today. 2018, 21, 22-37.

6. Frazier, W.E. Metal Additive Manufacturing: A Review. J. Mater. Eng. Perform. 2014, 23, 1917-1928.

7. Schultz, V.; Seefeld, T.; Vollertsen, F. Gap bridging ability in laser beam welding of thin aluminum sheets. Phys. Procedia. 2014, $56,545-553$.

8. Singh, R.; Gupta, A.; Tripathi, O.; Srivastava, S.; Singh, B.; Awasthi, A.; Rajput, S.K.; Sonia, P.; Singhal, P.; Saxena, K.K. Powder bed fusion process in additive manufacturing: An overview. Mater. Today. 2020, 26, 3058-3070.

9. Bandyopadhyay, A.; Bose, S. Additive Manufacturing. 1st ed.; CRC Press: Florida, USA, 2015, pp. 2-24.

10. Gibson, I.; Rosen, D.W.; Stucker, B. Additive Manufacturing Technologies: 3D Printing, Rapid Prototyping, and Direct Digital Manufacturing. Springer: New York, USA, 2009, pp. 4-38.

11. Joshi, S.C.; Sheikh, A.A. 3D printing in aerospace and its long-term sustainability. Virtual. Phys. Prototyp. 2015, 10, 175-185.

12. Nie, Z.G.; Wang, G.; McGuffin-Cawley, J.D.; Narayanan, B.; Zhang, S.J.; Schwam, D.; Kottman, M.; (Kevin)Rong, Y.M. Experimental study and modeling of $\mathrm{H} 13$ steel deposition using laser hot-wire additive manufacturing. J. Mater. Process. Technol. 2016, 235, 171-186.

13. Yan, W.Z.; Yue, Z.F.; Zhang, J.Z. Study on the residual stress and warping of stiffened panel produced by electron beam freeform fabrication. Mater. Des. 2016, 89, 1205-1212.

14. Chang, S.H.; Gach, S.; Senger, A.; Zhang, H.Y.; Du, D. A new 3D printing method based on non-vacuum electron beam technology. J. Phys.: Conf. Ser. 2018, 1074, 012017.

15. Chlebus, E.; Gruber, K.; Kuźnicka, B.; Kurzac, J.; Kurzynowski, T. Effect of heat treatment on the microstructure and mechanical properties of Inconel 718 processed by selective laser melting. Mater. Sci. Eng. 2015, 639, 647-655.

16. Criales, L.E.; Arisoy, Y.M.; Lane, B.; Moylan, S.; Donmez, A.; Ozel, T. Laser powder bed fusion of nickel alloy 625: Experimental investigations of effects of process parameters on melt pool size and shape with spatter analysis. Int. J. Mach. Tools Manuf. 2017, $121,22-36$

17. Ma, M.M.; Wang, Z.M.; Wang, D.Z.; Zeng, X.Y. Control of shape and performance for direct laser fabrication of precision largescale metal parts with 316L Stainless Steel. Opt. Laser Technol. 2013, 45, 209-216.

18. Yang, D.X.; Li, X.Y.; He, D.Y.; Nie, Z.R.; H, H. Optimization of weld bead geometry in laser welding with filler wire process using Taguchi's approach. Opt. Laser Technol. 2012, 44, 2020-2025.

19. Du,F.R.; Zhu, J.Q.; Ding, X.P.; Zhang, Q.; Ma, H.L.; Yang, J.; Cao, H.Z.; Ling, Z.M.; Wang, G.Y.; Duan, X.M.; Fan, S.Q. Dimensional characteristics of Ti-6Al-4V thin-walled parts prepared by wire-based multi-laser additive manufacturing in vacuum. Rapid Prototyp. J. 2019, 25, 849-856.

20. Yamamoto, M.; Shinozaki, K.; Kadoi, K.; Fujita, D.; Inoue, T.; Fukahori, M.; Kitahara, Y. Development of Hot-wire Laser Welding Method for Lap Joint of Steel Sheet with Wide Gap. Quarterly J. JWS. 2011, 29, 58-61.

21. Kadoi, K.; Shinozaki, K.; Yamamoto, M.; Owaki, K.; Inose, K.; Takayanagi, D. Development of High-efficiency / High-quality Hot-wire Laser Fillet Welding Process. Quarterly J. JWS. 2011, 29, 62-65. 